\title{
Operative Treatment of Isolated Split Greater Tuberosity Fracture (mutch type II) of Proximal Humerus with Modified PHILOS
}

\section{Gang Liu}

Affiliated Traditional Chinese Medicine Hospital of South-west Medical University

\section{Baolu Zhang}

South-west medical university

\section{Xiaoguang Guo}

Affiliated TCM hospital of south-west medical university

\section{Shengqiang Zeng}

Affiliated TCM hospital of south-west medical university

\section{Kai Deng}

Affiliated TCM hospital of south-west medical university

\section{Guoyou Wang}

Affiliated TCM hospital of south-west medical university

Shijie Fu ( $\nabla$ fushijieggj@126.com )

\section{Research article}

Keywords: Isolated Split GT Fracture, Modified PHILOS Plate, Hollow Screw

Posted Date: February 20th, 2020

DOI: https://doi.org/10.21203/rs.2.24099/v1

License: (c) (1) This work is licensed under a Creative Commons Attribution 4.0 International License. Read Full License 


\section{Abstract}

Background: The greater tuberosity (GT) of the proximal humerus is the attachment point of the rotator cuff, which plays a role in the movement of the shoulder joint and is the core of the entire shoulder joint.

Material and Methods: In our current study, 40 patients with isolated split GT fracture (mutch type II) from july 2017 to January 2019, which was typed by J.Mutch professor, Canada in 2014, were employed in the study. They were divided into two groups: the Modified PHILOS plate group (group $A, n=20$ ) and the Hollow Screw group (group B, $n=20$ ). The functional scores Constant-Murley Score (CMS), American Shoulder and Elbow Surgeons (ASES), The University of California at Los Angeles shoulder rating scale (UCLA) and Visual Analogue Score (VAS) were recorded in both pre-op and post-op last follow.

Results: Compared with last-follow, all shoulder scores (CMS, ASES, and UCLA) of group A was significantly better than group $B(P<0.05)$, but VAS $(P>0.05)$. Moreover, in post-op complications, there were one GT malunion and one shoulder pain in group $A$, but in group $B$, there were seven GT disappear (35\%), three GT malunion and two patients with repeated shoulder pain.

Conclusion: The Modified PHILOS plate in treating isolated split GT fracture (mutch type II) was found to be effective than hollow screw in the short term follow. However, there are still some post-op complications in both groups. Keywords : Isolated Split GT Fracture; Modified PHILOS Plate; Hollow Screw

\section{Background}

Proximal humeral fractures (PHFs) [1] is the third common fractures in the elderly, followed by the proximal femur and distal radius, accounting for $5 \%$ of the total body [2]. Isolated GT fractures were accounting for $15 \%-20 \%$ of PHFs. Numerous surgical methods in treating PHFs have been described, with Proximal Humeral Interlocking Plate (PHILOS) considered to be the "gold standard" [3-6]. However, in 2005, Kim E had reported patient with isolated GT fracture of PHFs has different characteristic, so their treatment and classification should be considered separately from that for other PHFs [7]. As is known to all, the shortest PHILOS plate is 91 millimeter with three locking holes to fix humeral shaft in PHFs. Isolated Mutch type II GT fracture has only one large fracture fragment, and we should use a small and shorter plate to fix that fragment. So we cut off the shaft PHILOS plate and leave a 48 millimeter plate for use, which has a shorter length, incision and avoids the lesion of the axillary nerve.

In the past decades, many types were suggested to guide the treatment of PHFs and the most widely accepted classical were Neer and AO typing. In 1970, Neer divided PHFs into four partial fractures, which displaced more than $1 \mathrm{~cm}$ is considered to be appropriate for surgical treatment [8]. In recent years, many people began to pay more attention to GT fractures [9-10]. However, the two classical typing did not differentiate the isolated GT fracture. Moreover, the size, shape and fragment movement of the GT fragment could reflect different injury mechanisms. On the other hand, the morphology fracture fragment also influenced the choice of specific surgical methods. 
In 2014, the GT fractures were further divided into three types: avulsion, split and depressed by professor J.Mutch in Canada, in which split fracture of the GT (as specific Fig. 1.II) was the most common, accounting for the $41 \%$ of entire fracture of the GT [11]. With that background, we tried to use this new morphology type and modified traditional PHILOS plate fixation in our study.

\section{Material And Methods}

\section{Ethical statement}

All procedures were approved by the Ethical Committee of Affiliated Traditional Chinese Medicine Hospital of Southwest Medical University (SWMCTCM2017-0710) and performed by the 1964 Helsinki declaration and amendments or comparable ethical standards. The specific illustration and agreement were obtained from all individual participants included in our study.

\section{Inclusion Criteria}

Patients were employed to meet such inclusion criteria: i) Aged 18-80, patient's history, physical examination, X-Ray and CT (2D and 3D) should conform to the humeral fractures of GT. ii) Confirmed isolated Mutch II (split) GT fracture of the proximal humerus, (2 people assessed respectively, and if there were any divergences to the results of the classification, it would be given to the third person to take a comprehensive evaluation and got the final results included in this experiment. iii) The patient and family members were willing to cooperate with the postoperative treatment. Then the doctor illustrated the advantages and disadvantages of surgical and the study plan before an operation. Finally, the patient and the family signed on the agreement.

\section{Exclusion Criteria}

Other Patients should be excluded with such criteria: i) Type Mutch I or III of humeral GT fracture. ii) Patient whoever was followed up less than one year and did not cooperate with the medical staff for postoperative follow-up evaluation. iii) Patients with complications such as severe neurological and vascular injury. iv) The patient who had a history of mental illness or epilepsy or who are medicine or narcotic abuser.

\section{Pre-op assessment}

On admission, asking disease history in detail to be familiar with the time and mechanism of injury. Judged their ROM through the shoulder examination and X-ray, CT (3D), and MRI should be taken, especially for CT scan. According to the author's experience, the fracture fragment showed better on CT (3D), which was very important for specific plans and assessments before surgery. Therefore, we recommended that all patients should have CT (3D), and MRI could better understand whether the patient had combined rotator cuff lesion, to make a comprehensive strategy.

\section{Surgical technique}


Group A: Modified PHILOS plate; with satisfactory anesthesia, patients were placed in the beach chair position, and taken the split deltoid incision; sharply and bluntly separated subcutaneous tissue, deep fascia, muscle, and other tissues layer-by-layer, until the fracture was exposed. (Noted to protect the axillary nerve, marked and protected Posterior humeral circumflex artery). On the other hand, we prepared the modified PHILOS plate and cut off the three holes screw on the shaft. Moreover, the fragment was accurately fixed by K-wires, and the modified plate was at $5 \mathrm{~mm}$ under the top of the GT and the medial intertubercular sulcus. The correct position was checked with fluoroscopy. Finally, fragment reduction and screw length were ensured by fluoroscopy.

Group B: The hollow screw; the same preparation as group A. Then, $2.0 \mathrm{~K}$-wires wires were used to have reduction and fixation under fluoroscopy in a $90^{\circ}$. (Note: The direction of the inserting needle should not be parallel to the biomechanical direction of the supraspinatus muscle pull as far as possible; the best position was to form an angle and increase the fixation biomechanics). Two K-wires were used to fix fracture fragments, and then, the $\mathrm{C}$-arm was used to fluoroscopy reset effect. If the reset effect was not effective as expected, adjust its position until having a reduction. Screws have been fixed by the guidance K-wire.

\section{Postoperative review and functional exercise}

Functional exercises were started two days after the operation. The arm was supported by a sling for three weeks, which was protected at the abduction of 45 degrees. We tried to avoid making the fixed GT fragment displacement via the supraspinatus or shoulder activities. Passive motion exercises began in the third weeks of operation. Active motion exercises and strengthening exercises were started at six weeks after surgery. Further continual follow-ups were carried out at every 1, 3, 6 and 12 months at least after surgery. The functional scores Constant-Murley Score (CMS), American Shoulder and Elbow Surgeons (ASES), the University of California at Los Angeles shoulder rating scale (UCLA) and Visual Analogue Score (VAS) were assessed in both pre-op and post-op final follow.

\section{Statistics}

SPSS 17.0 statistical software was used for data analysis. The gender and injury sites (left and right) of the two groups included in the $A$ and $B$ groups were analyzed by chi-square test, indicated by $c^{2}$. The data of Shoulder function scores of CMS, ASES, UCLA, and VAS in the two groups were expressed as the mean \pm standard deviation $( \pm S$ ) analyzed by independent samples $t$ test. The test level was $a=0.05$.

\section{Results}

\section{The pre-op baseline}

Compared with group A and group B, there were no significant statistical differences in ages, gender, injured sites (left and right) and injured time between them $(P>0.05)($ Table 1$)$. 
Table 1

The pre-op baseline comparion of group A and B

\begin{tabular}{|c|c|c|c|c|c|}
\hline \multicolumn{2}{|l|}{ Contents/groups } & Group A $(n=20)$ & Group B $(n=20)$ & Statistics & $P$ value \\
\hline \multicolumn{2}{|l|}{ Ages } & $61.90 \pm 2.40$ & $62.90 \pm 2.22$ & $t=1.366$ & 0.18 \\
\hline \multicolumn{2}{|l|}{ (Time/hours) } & $11.34 \pm 2.77$ & $11.60 \pm 2.49$ & $t=0.308$ & 0.76 \\
\hline \multirow[t]{2}{*}{ Gender } & Male & 12 & 7 & \multirow[t]{2}{*}{$\chi^{2}=0.50$} & \multirow[t]{2}{*}{0.48} \\
\hline & Female & 8 & 13 & & \\
\hline \multirow[t]{2}{*}{ Injured position } & Left & 12 & 9 & \multirow[t]{2}{*}{$x^{2}=0.90$} & \multirow[t]{2}{*}{0.34} \\
\hline & Right & 8 & 11 & & \\
\hline
\end{tabular}

\section{X-Ray}

As was shown in Fig 2, with post-op follow-up of 1, 6 and 12 months, we could learn that the mutch type II GT fractures with fixation of modified PHILOS might show better outcomes. Moreover, we could employ a shorter incision for the lower part of PHILOS had been cutting down. On the other hand, in Fig 3, we could see that in the post-op sixth month, the GT began to disappear (Fig 3.D) and this situation even worsens (Fig 3.E).

\section{Shoulder Functional Score}

The respectively pre-op and post-op last follow-up scores of A and B group are : CMS A group $39.75 \pm 2.53$, 92.84 \pm 1.92 , B group $40.65 \pm 2.49,85.12 \pm 2.47$; ASES group A $35.34 \pm 1.85,91.76 \pm 2.52$, group $B 36.41 \pm 2.53$, $88.38 \pm 2.72$; UCLA group A $15.30 \pm 2.20,34.23 \pm 2.64$, group B $15.00 \pm 2.01,29.50 \pm 2.28$, which shows that modified PHILOS plate is better than hollow screw (Fig 4. A-D \& Table 2) $(\mathrm{P}<0.05)$.

\section{Complications}

In our study, although we have gotten an acceptable shoulder function, there was still one GT malunion and one shoulder pain in group A. In group B, there were seven GT disappeared (35\%), three GT malunion and two patients with repeated shoulder pain.

\section{Table 2 Shoulder Functional Score}

The respectively pre-op and Last-follow scores of group A and B were: CMS group A $39.75 \pm 2.53$, 92.84 \pm 1.92 , B group $40.65 \pm 2.49,85.12 \pm 2.47$; ASES group A $35.34 \pm 1.85,91.76 \pm 2.52$, group $B 36.41 \pm 2.53$, $88.38 \pm 2.72$; UCLA group A $15.30 \pm 2.20,34.23 \pm 2.64$, group B $15.00 \pm 2.01,29.50 \pm 2.28$, which shows that modified PHILOS plate is better than hollow screw (Fig 4. A-D) $(P<0.05)$. 


\begin{tabular}{|lllll|}
\hline & Group A & \multicolumn{3}{l|}{ Group B } \\
\cline { 2 - 5 } & Pre-operation & Last-follow & Pre-operation & Last-follow \\
\hline CMS & $39.75 \pm 2.53^{\mathrm{ab}}$ & $92.84 \pm 1.92^{\mathrm{b}}$ & $40.65 \pm 2.49^{\mathrm{ab}}$ & $85.12 \pm 2.47$ \\
\hline ASES & $35.34 \pm 1.85^{\mathrm{ab}}$ & $91.76 \pm 2.52^{\mathrm{b}}$ & $36.41 \pm 2.53^{\mathrm{ab}}$ & $88.38 \pm 2.72$ \\
\hline UCLA & $15.30 \pm 2.20^{\mathrm{ab}}$ & $34.23 \pm 2.64^{\mathrm{b}}$ & $15.00 \pm 2.01^{\mathrm{ab}}$ & $29.50 \pm 2.28$ \\
\hline
\end{tabular}

Note: a: $p<0.05$, compared with Last-follow in the same group; $b: p<0.05$, compared with group $B$.

\section{Discussion}

With the consideration of the fracture fragment size and shape, isolated GT fracture is divided into three morphological classifications by professor J.Mutch with X-Ray evaluation. Type I avulsion fracture, fragment is small and the fracture line is horizontal; Type II split fracture, the fragment is large, and the fracture line is vertical. The mechanism of injury may be the impact on the anterior upper surface of the glenoid when the shoulder joint is dislocated or subluxate; Type III depressed fracture is a downwardly displaced fracture block. Under the study of professor J.Mutch, avulsion, split and depressed fracture of greater tuberosity respectively account for a proportion of 39\% (77/199), 41\%(81/199), 20\%(41/199). At the same time, Mutch classification compared the reliability of Neer, which mean the morphological type of the greater tuberosity is better than the Neer and $A O$ types. Conservative and surgical treatment in displaced fractures of the GT had been reported [12-15]. Park TS recommended that GT fractures with a displacement greater than $5 \mathrm{~mm}$ should be treated operatively [16]. On the other hand, Rath $\mathrm{E}$ had shown that conservative treatment with a displacement of less than $3 \mathrm{~mm}$ could achieve clinical results [17-18]. In our study, isolated GT fracture, J.Mutch type, was employed to be our diagnosis. Mover, treatment and investigation algorithm reviewed by professor Rouleau DM, was also adopted in this research. However, this classification also had some disadvantages. As is shown in Fig 3.B, there are numerous fragments in isolated split GT fracture (Mutch type II), which is difficult for us to fix it all. So, advanced imaging, such as MRI should be taken to a specific diagnosis. Complications, such as rotator cuff tear may play an important role in this fracture.

Previously, it is well known that the PHILOS plate advanced to the implant of choice in treating displacement PHFs [19-23]. Numerous surgical methods have been reported in treating split-type GT (Mutch II) fractures, such as double-row suture-bridge, inter-fragmentary compression screws, or a small locking plate. So, we cut off the three holes on PHILOS shaft and use the head of a plate only, which makes it be a small locking plate. In our study, Compared with last-follow, all shoulder scores (CMS, ASES, and UCLA) of group A was significantly better than group $B(P<0.05)$, but VAS $(P>0.05)$. Our results show that the Modified PHILOS provides a stable fixation and patients get a better functional outcome. Moreover, the modified PHILOS has some specific advantages as follows. It is a small locking plate shorter than normal PHILOS plate, especially good for elder patients with osteoporosis. We can employ a 
small incision and protect the soft tissue. However, the cost-effectiveness is higher than hollow screw group. Furthermore, the modified PHILOS can't fix the super-posterior part of GT fracture with multiple fragments, and this may be one of the reasons cased shoulder dysfunction. On the other hand, a hollow screw is cheaper than modified PHILOS. Additionally, we fix the fragment with a percutaneous way, which has a smaller incision, and less soft tissue lesion [24]. But it is hard for us to perform it on osteoporosis patients.

Older patients with more than 60 years are likely to sustain PHFs [25-26]. In our study, we employ patients at an average age of $63.20 \pm 1.70$ and $59.90 \pm 2.10$ in group $A$ and $B$ and those who have osteoporosis have a higher risk, especially in hollow screw group. GT disappeared (35\%) in group A is one of the common complications in our study. The number of screws overused in our research is one of reasons that causes the GT disappeared. Man-made comminuted GT fracture would be shown during the operation. With the traction of the infraspinatus and teres minor, fragments are likely to displace at superposterior part of the proximal humerus. Furturemore, hollow screw can't provide stable fixation and strong biomechanics, which makes fragments fretting. On the other hand, the blood supply is damaged when fracture happened, GT malunion is showed up during the follows. With the displaced super-posterior GT fragment, subacromial impingement is a common cause of shoulder pain in both group A and B. In a comparison of a modified PHILOS plate and screw, plates are found to be stronger biomechanics, stable fixation in osteoporosis patients, which provide a better shoulder function.

However, our study also has some limitations. i) The modified PHILOS plate does not fix the superposterior fragments of GT. ii) J.Mutch type was only assessed by X-ray without 3D CT and MRI, which can't provide a better assessment of whether the fracture combines with rotator cuff tears and the number of fragments. If the rotator cuff tear is included, it is better for us to use suture anchor when fixing the fracture. In later studies, MRI should be performed routinely. iii) We have no idea about vascular injury occurred when GT fracture happened, and this might affect results of GT disappeared and malunion. iv)The patients participating in this study were all chosen from the same hospital, and the number of cases was small. There were geographical limitations, and the operator was a professor who had studied in Germany with extensive experience in the shoulder joint.

\section{Conclusion}

It is necessary to classify and treat subtypes of greater tuberosity alone. Morphological types for GT fracture is simply and practically. However, the classification does not enroll the injury mechanism and biomechanics, and the mechanism of the injury need to be considered in the process of clinical surgery, which aims at restoring mechanism balance biomechanical of rotator cuff. Under the guidance of this classification, the Modified PHILOS plate in treating Mutch type II GT fractures was found to be effective than hollow screw in the short term follow. However, there are still some post-op complications in both groups. 


\section{Abbreviations}

GT: Greater Tuberosity; CMS: Constant-Murley Score; ASES: American Shoulder and Elbow Surgeons; UCLA: University of California at Los Angeles; VAS: Visual Analogue Score; PHFs: Proximal humeral fractures; PHILOS: Proximal Humeral Interlocking Plate

\section{Declarations}

\section{Acknowledgments}

Not applicable

\section{Funding}

This study was supported by the Modern design and research project of the research base on philosophy and Social Sciences of Sichuan in 2018 (Number: MD18E014) and Academician Workstation Construction Project of Luzhou, Sichuan Province, China. (No. 20180101).

\section{Availability of data and materials}

The datasets used and analysed during the current study available from the correspond-

ing author on reasonable request.

\section{Authors' contributions}

GL and SJF contribute to conception and design of study. BLZ and XGG contribute to

-follow the development of study. SQZ contribute to write and editing this manuscript. GL and KD contribute to data collection and literature search. All authors read and approved the final manuscript.

\section{Ethics approval and consent to participate}

This study was approved by the Ethical Committee of Affiliated Traditional Chinese Medicine Hospital of Southwest Medical University with the following number: SWMCTCM2017-0710.

\section{Consent for publication}

Not applicable

\section{Competing interests}

The authors declare that they have no competing interests.

\section{References}


1. Bell JE, Leung BC, Spratt KF, et a1. Trends and variation in incidence, surgical treatment, and repeat surgery of proximal humeral fractures in the elderly. J Bone Joint Surg Am. 2011;93:121-31.

2. Geiger EV, Maier M, Kelm A, et al. Functional outcome and complications following PHILOS plate fixation in proximal humeral fractures. J Acta Orthop Traumatol Turc. 2010;44:16.

3. Kannus P, Palvanen M, Niemi S, et a1. Rate of proximal humeral fractures in older Finnish women between 1970 and 2007. Bone. 2009;44:656-9凶

4. Maman E, Dolkart O, Chechik O, et a1. Arthroscopic findings of coexisting lesions with greater tuberosity fractures. Orthopedics. 2014;37:272-7.

5. Lill H, Katthagen C, Jensen G, et al. Arthroscopic fracture management in proximal humeral fractures. Unfallchirurg. 2013;116:296-304.

6. DeBottis D, Anavian J, Green A, et al. Surgical management of isolated greater tuberosity fractures of the proximal humerus. Orthop Clin North Am. 2014;45: 207-18.

7. Kim E, Shin HK, Kim CH. Characteristics of an isolated greater tuberosity fracture of the humerus. J Orthop Sci. 2005;10:441-4.

8. Neer CS. Displaced proximal humeral fractures. I. Classification and evaluation. J Bone Joint Surg Am. 1970;52:1077-89.

9. Rouleau DM, Laflamme GY, Mutch J. Fractures of the greater tuberosity of the humerus: a study of associated rotator cuff injury and atrophy. Shoulder Elbow. 2016;8:242-9.

10. Bureau NJ, Blain-Paré E, Tétreault P, et al. Sonographic Visualization of the Rotator Cable in Patients With Symptomatic Full-Thickness Rotator Cuff Tears: Correlation With Tear Size, Muscular Fatty Infiltration and Atrophy, and Functional Outcome. J Ultrasound Med. 2016;35:1899-905.

11. Mutch J, Laflamme G, Hagemeister N, et a1. A new morphological classification for greater tuberosity fractures of the proximal humerus: validation and clinical implications. Bone Joint J. 2014;96-B:646-51. 12. Rath E, Alkrinawi N, Levy O, et al. Minimally displaced fractures of the greater tuberosity: outcome of non-operative treatment. J Shoulder Elbow Surg. 2013;22:8-11.

13. Platzer $P$, Thal hammer $G$, Oberleitner $G$, et al. Displaced fractures of the greater tuberosity: a comparison of operative and non-operative treatment. J Trauma. 2008;65(4):843-8.

14. Yin B, Moen TC, Thompson SA, et al. Operative treatment of isolated greater tuberosity fractures: a retrospective review of clinical and functional outcomes. Orthopedics. 2012;35:807-14.

15. Li R, Cai M, Tao K. Arthroscopic reduction and fixation for displaced greater tuberosity fractures using the modified suture-bridge technique. Int Orthop. 2017;41:1257-63.

16. Park TS, Choi IY, Kim YH, et a1. A new suggestion for the treatment of minimally displaced fractures of the greater tuberosity of the proximal humerus. Bull Hosp Jt Dis. 1997;56:171-6.

17. Rath E, Alkrinawi N, Levy O, et al. Minimally displaced fractures of the greater tuberosity: outcome of non-operative treatment. J Shoulder Elbow Surg. 2013;22:e8-11.

18. Rouleau DM, Mutch J, Laflamme GY, et a1. Surgical treatment of displaced greater tuberosity fractures of the humerus. J Am Acad Orthop Surg. 2016;24:46-56.

19. Strohm PC, Helwig P, Konrad G, et a1. Locking plates in proximal humerus fractures. Acta Chir Orthop Traumatol Cech. 2007;74:410-5.

20. Drosdowech DS , Faber KJ, Athwal GS. Open reduction and internal fixation of proximal humerus 
fractures. Orthop Clin North Am. 2008;39:429-39.

21. Schliemann B, Wähnert D, Theisen C, et al. How to enhance the stability of locking plate fixation of proximal humerus fractures? An overview of current biomechanical and clinical data.Injury.2015;46:120714.

22. Cho $\mathrm{CH}, \mathrm{Kim} \mathrm{DH}$, Kim BS. Radiographic and clinical results of tension suture fixation using two washers with PHILOS plate for proximal humeral fractures. Injury. 2017;48(2):464-8.

23. White EA, Skalski MR, Patel DB, et al. Isolated greater tuberosity fractures of the proximal humerus: anatomy, injury patterns, multimodality imaging,and approach to managment. Emerg Radiol. 2018;25:235-46.

24. Bogdan $Y$, Gausden EB, Zbeda R, et a1. An alternative technique for greater tuberosity fractures: use of the mesh plate. Arch Orthop Trauma Surg. 2017;12:1067-70.

25. Lind T, Krøner K, Jensen. The epidemiology of fractures of the proximal humerus. Arch Orthop Trauma Surg. 1989;108:285-7.

26. Warden SJ , Carballido-Gamio J, Avin KG, et a1. Adaptation of the proximal humerus to physical activity A within-subject controlled study in baseball players. Bone. 2019;121:107-15.

\section{Figures}


The Mucth Type of Isolated Greater Tuberosity Fracture

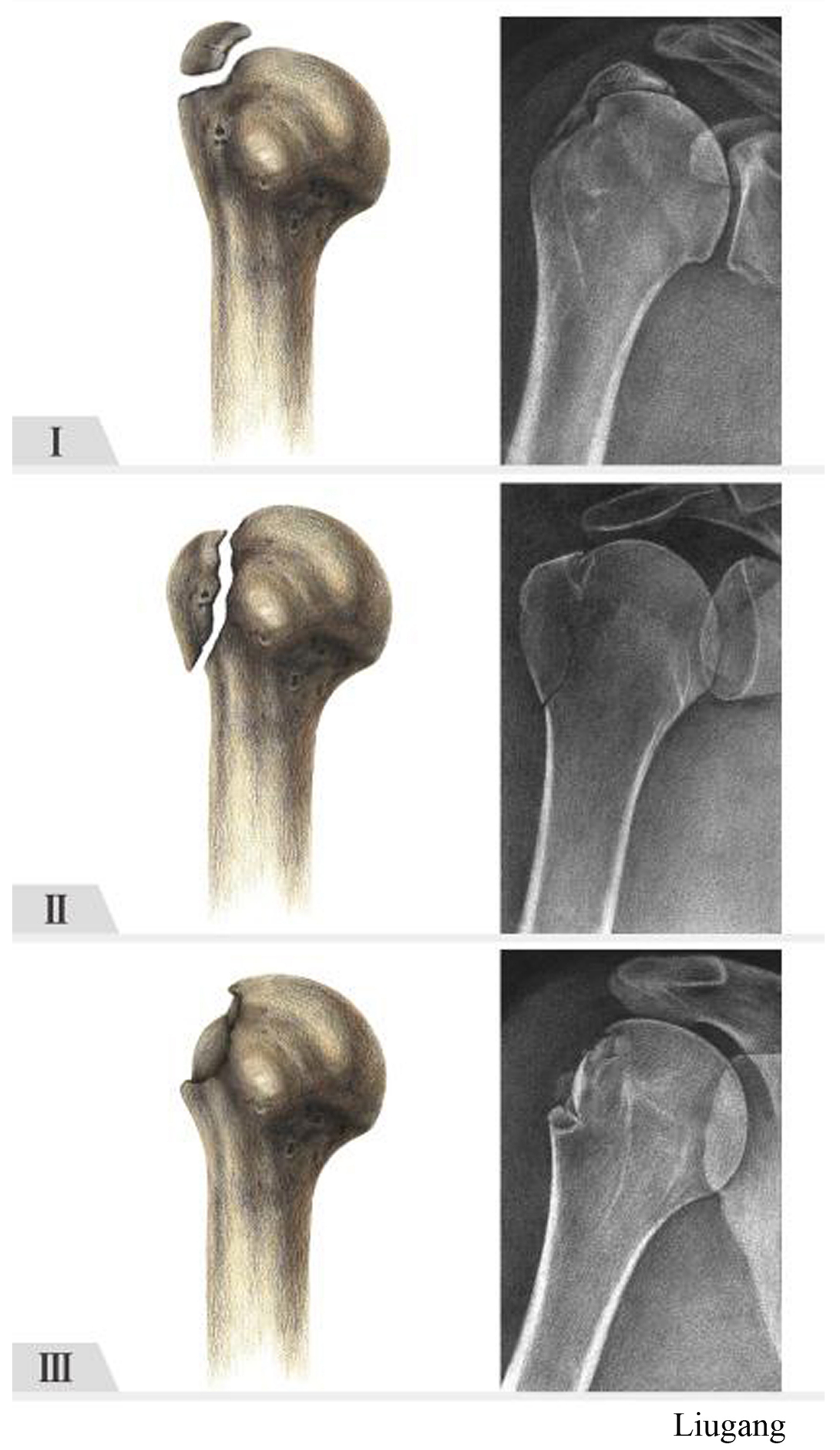

\section{Figure 1}

The Morphology Classification of Isolated Humerus Greater tuberosity fracture. Type I avulsion fracture involves small fragments of bone with a horizontal fracture line. Type II split fracture involves a large fragment with a vertical fracture line. Type III depressed fracture involves a fragment that is displaced inferiorly. 

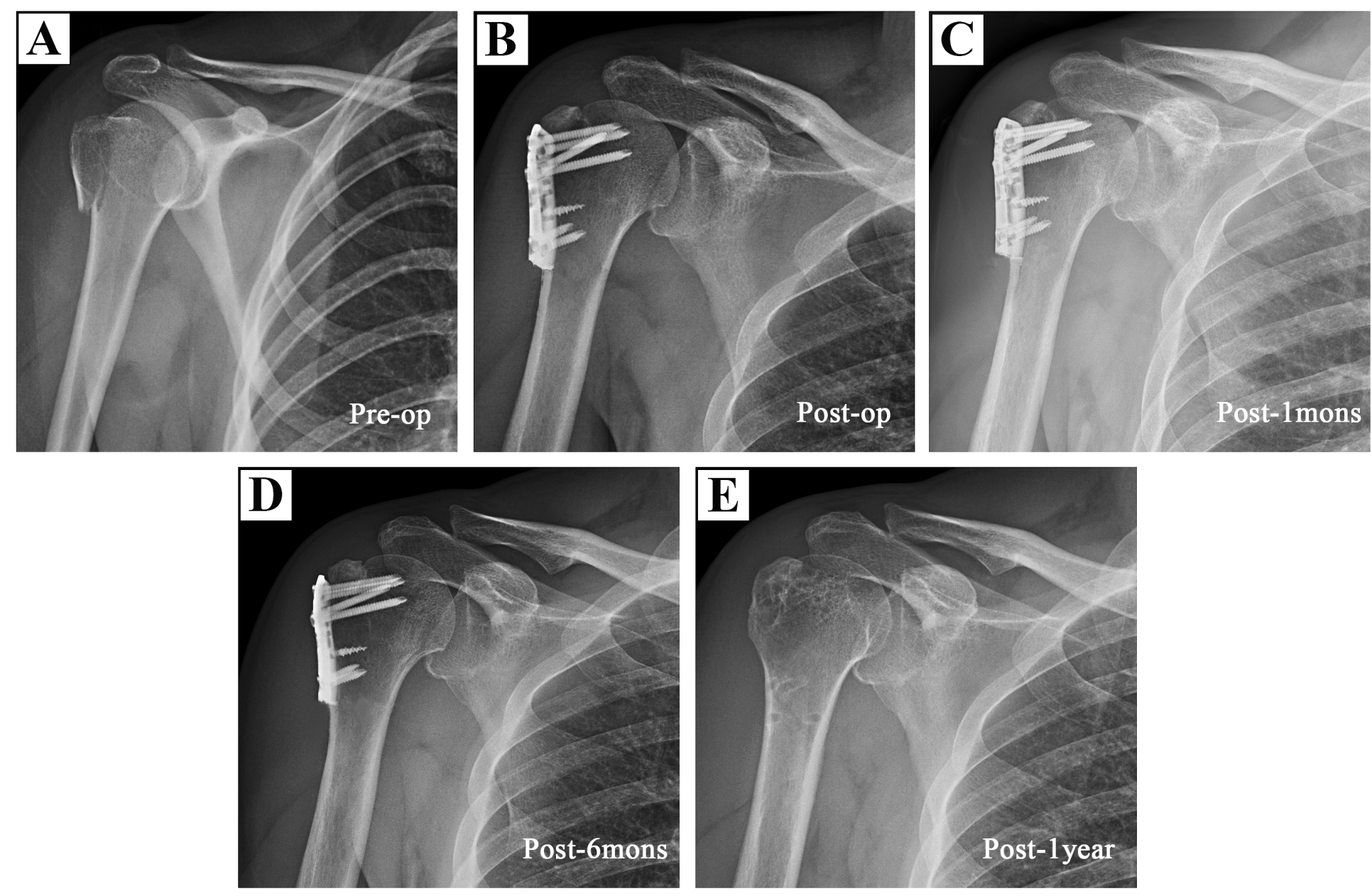

\section{Figure 2}

The Modified PHILOS Plate Group. (A) Anterior and posterior pre-op of X-ray. (B) Post-op of X-ray. (C) Post-op one month of X-ray. (D) Post-op sixth months of X-ray. (E) Post-op one year of X-ray. 

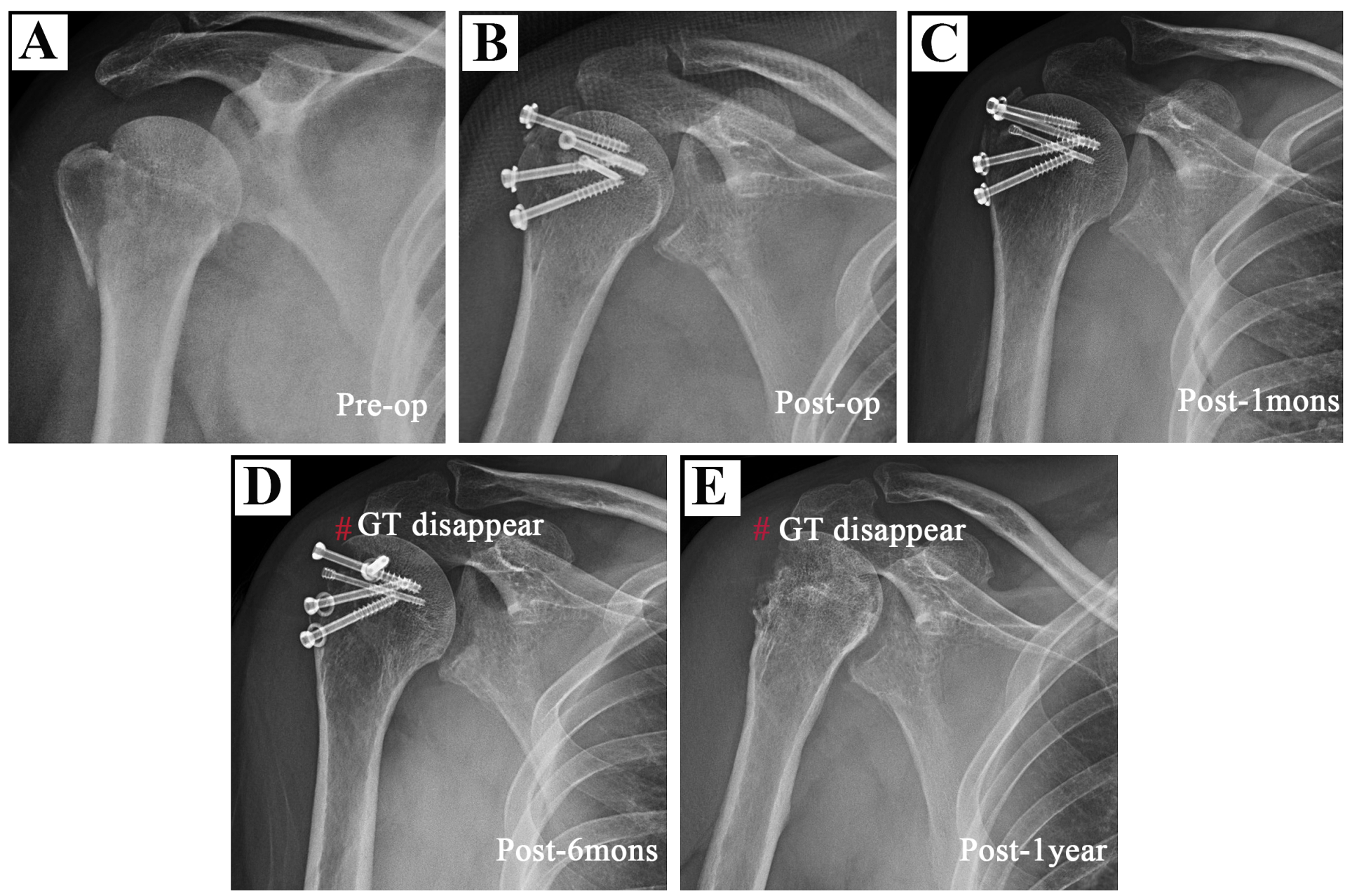

\section{Figure 3}

The Hollow Screw Group. (A) Anterior and posterior pre-op of X-ray. (B) Post-op of X-ray. (C) Post-op one month of X-ray. (D) Post-op sixth months of X-ray with GT disappeared. (E) Posterior post-op one year of X-ray GT disappeared. 
A

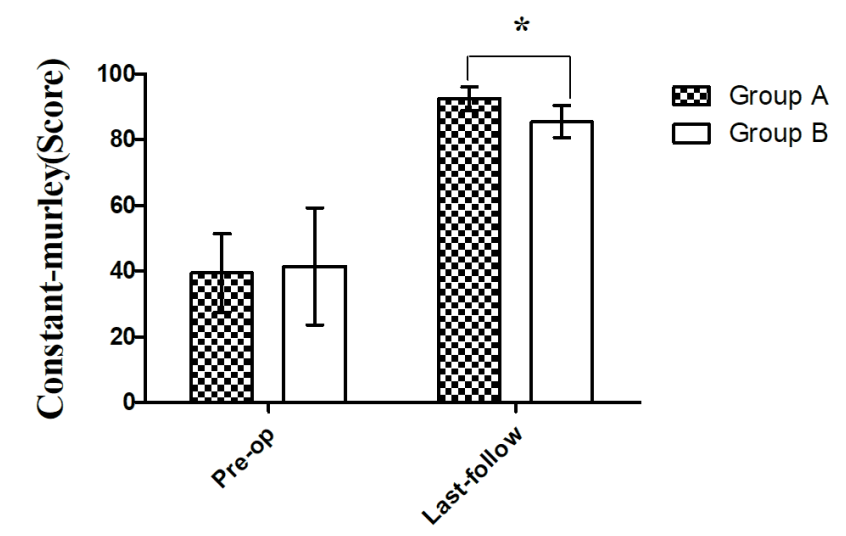

C

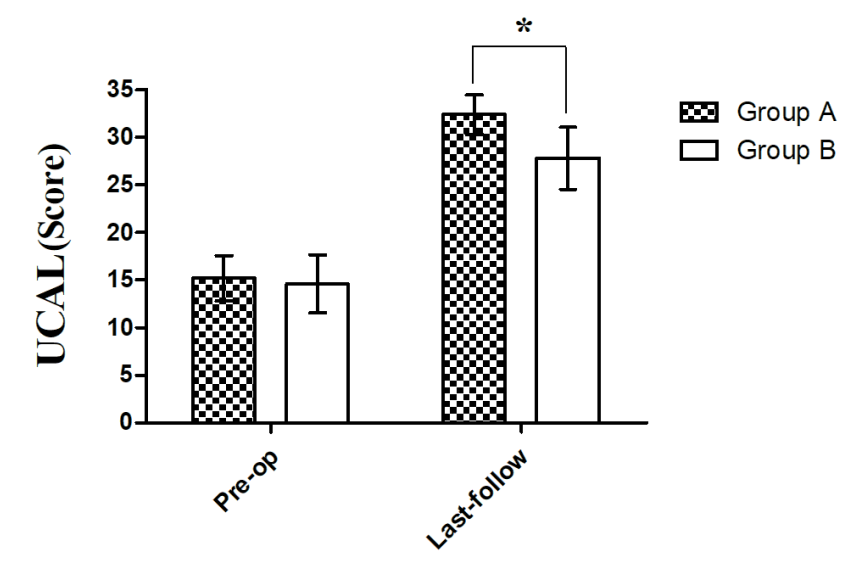

B

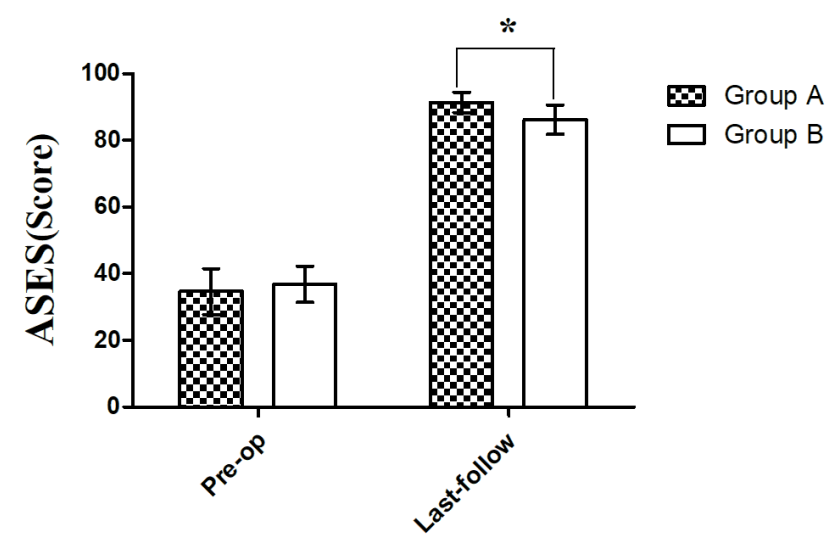

D

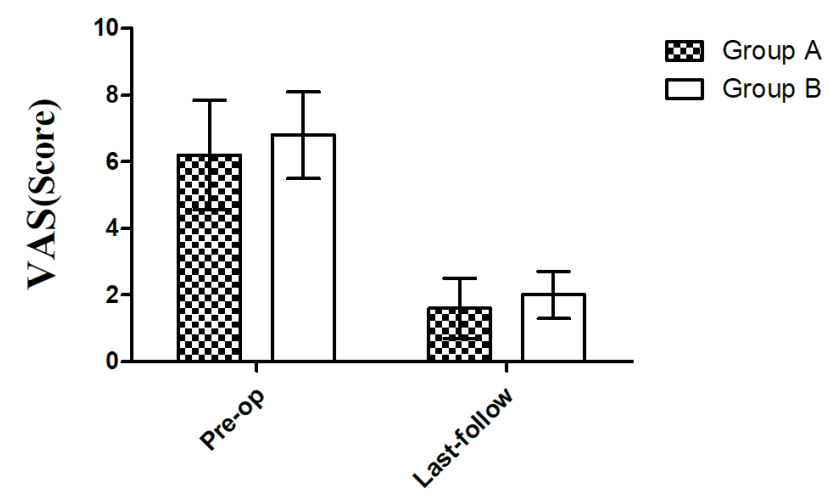

Figure 4

The Assessment of Shoulder Function Between two Groups. (A) Constant Murley Score (CMS). (B) American Shoulder and Elbow Surgeons (ASES). (C) The University of California at Los Angeles shoulder rating scale (UCLA). (D) Visual Analogue Score (VAS). ${ }^{\star} \mathrm{P}<0.05$ vs. group $A$ (post-op functional score).

\section{Supplementary Files}

This is a list of supplementary files associated with this preprint. Click to download.

- Data.xlsx 